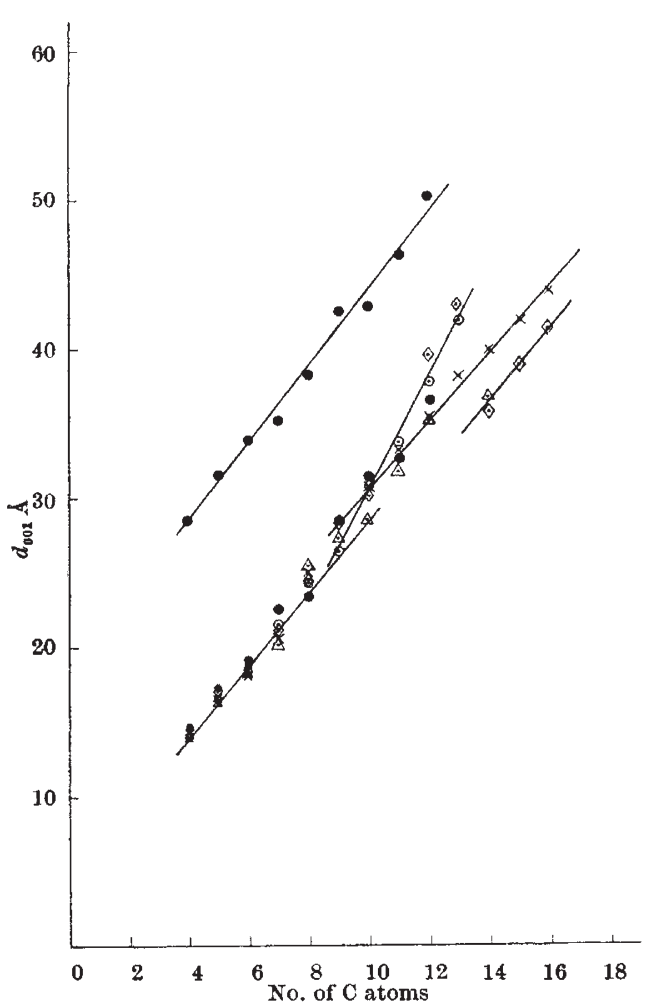

Fig. 2. Spacing variations for substances dried at $60^{\circ} \mathrm{C}$. $x, \mathrm{HS} 3 / 1 ; \odot, \mathrm{HC} 6 / 1 ; \Delta, \mathrm{HC} 4 / 1 ; \odot, \operatorname{HCS} 5 / 1 / 2$

From the slope of the graphs, the orientation and quantity of molecular layers can be deduced. In general, the slope is of the order of $2 \cdot 3-2 \cdot 9 \AA / \mathrm{C}$ atom, indicat. ing two erect layers of molecules; but for certain substances, HC 6/1, HS 4/1 (at room temperature) and HCS (at $60^{\circ} \mathrm{C}$ ), a slope of $3.5-3.9$ is found, possibly due to the existence of three erect layers.

With alcohols, the hydroxy-salts form $\beta$-complexes with difficulty, and only in isolated cases. Aromatic substances (anthranilic acid, hippuric acid, naphthol yellow and others) give large-spacing $\beta$-complexes.

\section{Jesús Cano-Ruiz}

Douglas M. C. MacEwan

Departamento de Química Inorgánica,

Araceli Ramírez Garcfa

Facultad de Ciencias,

Universidad de Madrid, Spain.

' Cano-Ruiz, J., and MacEwan, D. M. C., Nature, 176, 1222 (1955)

${ }^{2}$ Cano-Ruiz, J., and MacEwan, D. M. C., III Reunión Int. React. Sólidos Madrid, 1 (1957).

'Ramírez Garría, Araceli, Cano-Ruiz, J., and MacEwan, D. M. C., Nature, 203,1063 (1964).

4 Aragón de la Cruz, F., Cano-Ruiz, J., and MacEwan, D. M. C., Nature, 183 740 (1959).

'Cano-Ruiz, J., Estéban, J. M., and Gutiérrez Rios, E. Anal. Fis y Quim. (in the press\%.

- Feitknecht, W., Fortschr. Chem. Forsch., 2, 670 (1953)

' Cruz Cumplido, Maribel, Cano-Ruiz, J., and MacEwan, D. M. C., Natur wissenschaften, 51,482 (1964)

\section{RADIATION CHEMISTRY}

\section{Short-lived Radicals in Irradiated Glycine}

Several investigators have used the electron spin resonance technique to measure the numbers of stable free radicals induced by ionizing radiation in aminoacids ${ }^{1-4}$. The observation that at doses in the M.rad region the radical yield does not increase linearly with the absorbed dose but tends towards saturation was explained by Rotblat and Simmons ${ }^{4}$ as being due to a back reaction between stable and unstable radicals, but as their nature was still in some dispute at that time no details of the mechanism were attempted. The availability of new evidence concerning the radical species has now prompted further investigation of this problem.

If the electron spin resonance measurements can be made only after the irradiation has been completed, it is not possible to observe radicals with life-times less than about 10 sec at room temperature. In some cases, however, it may be possible to stabilize such radicals by irradiating at low temperatures, and this has been done by Henriksen for frozen aqueous solutions of glycine ${ }^{5}$. He was thus able to show that the water component gave rise to $\mathrm{OH}$ radicals plus an unidentified species, while the glycine gave rise to ${ }^{+} \mathrm{NH}_{3} \mathrm{CHOO}^{-}$and $\cdot \mathrm{CH}_{2} \mathrm{COO}-$. Very recently the use of carbon-13 has enabled this proposal to be confirmed for pure glycine ${ }^{6}$. It seems likely that these were the radicals detected by ultra-violet absorption during the pulse radiolysis of glycine solutions at room temperature?

Since these organic radicals retain their specific orientation within the molecule after their formation ${ }^{8}$, it seems unlikely that they can move at all in the dry powder. Hence the reactive transients must be the unobserved fragments, namely, $\mathrm{NH}_{3}^{+}$(complementary to $\cdot \mathrm{CH}_{2} \mathrm{COO}^{-}$) and $\dot{\mathrm{H}}$ (complementary to $+\mathrm{NH}_{3} \mathrm{CHOO}-$ ). Ammonia formed from the neutralization of $\mathrm{NH}^{+}$was not detected at room temperature, but it was observed when the powder was heated to $120^{\circ} \mathrm{C}$ (ref. 9). This effectively eliminates $\mathrm{NH}_{3}^{+}$as the attacking radical as it could not be sufficiently mobile at room temperature. It therefore seems most probable that hydrogen atoms are the reactive species in the solid material. If this is true, then not only can each $\dot{H}$ attack and neutralize one of the observable radicals, but it can also react with another $\dot{\mathrm{H}}$ to form molecular hydrogen which should then be detectable after irradiation of glycine. Accordingly an experiment was devised to test this hypothesis.

A sample consisting of $1 \mathrm{~g}$ of dry 'AnalaR' grade glycine was evacuated to $5 \times 10^{-5}$ torr in a glass tube and sealed. It was then irradiated with 50 M.rads using the $15-\mathrm{MeV}$ electron linear accelerator at St. Bartholomew's Hospital, London. Afterwards the sample tube was connected to a mass spectrometer (Associated Electrical Industries Type $M S 10$ ) tuned to mass number 2 , and the vacuum seal opened. A large positive reading was obtained, from which it was concluded that about $3 \times 10^{-7} \mathrm{~g}$, corresponding to about $10^{17}$ molecules, had been present. A check with unirradiated glycine was completely negative, while a check on an empty glass sample tube given 50 M.rads showed a signal the amplitude of which was just a few per cent of that from the glycine. It was thus confirmed that hydrogen is a product of irradiated glycine, and accordingly it is concluded that atomic hydrogen is the reactive, short-lived radical previously postulated ${ }^{4}$ to account for the shape of the yield-dose curves for stable radicals.

I thank Prof. J. Rotblat for the use of the linear accelerator, and Mr. D. J. Pacey of Brunel College for his assistance with the mass spectrometer measurements.

\section{J. A. Srmmons}

Medical Research Council,

Experimental Radiopathology Research Unit, Hammersmith Hospital,

Ducane Road, London, W.12.

${ }^{1}$ Prydz, S., and Henriksen, T., Acta Chem. Scand., 15, 791 (1961).

${ }^{2}$ Randolph, M. L., Symp. Free Radicals in Biological Systems, chapter 19 (Academic Press, 1961)

'Tohnlein, W, and Muller, A., Phys, Med. Biol., 6, 599 (1962)

"Rotblat, J., and Simmons, J. A., Phys. Med. Biol., 7, 489 (1963).

${ }^{5}$ Henriksen, T., Rad. Res., 17, 158 (1962).

- Morton, J. R., J. Amer. Chem. Soc., 86, 2325 (1964).

7 Greenstock, C. L., and Rollinson, E. R., Nature, 201, 812 (1964).

${ }^{8}$ Whiffen, D. H., in ref. 2 , chapter 17 .

Simmons, J. A., Ph.D. thesis, Univ. of London (1960). 